\title{
OS TRES PORQUINHOS E AS TEMPORALIDADES DA INFÂNCIA
}

\author{
Patrícia Dias Prado*
}

\begin{abstract}
RESUMO: Tendo como alegoria de análise das temporalidades da infância uma edição atual da clássica história Os três porquinhos, articulada com os dados coletados em minha pesquisa de doutorado sobre as relações etárias entre crianças pequenas em uma instituição de educação infantil pública, proponho a reflexão sobre a construção social das idades da infância no capitalismo em contraponto com as capacidades de sociabilidade e de produção das culturas infantis pelas meninas e meninos, menores e maiores no coletivo educativo.

Palavras-chave: Educação infantil. Relações de idade. Literatura infantil. Criança pequena. Temporalidade.
\end{abstract}

\section{THE THREE LITTLE PIGS AND THE CHILDHOOD MULTIPLICITY OF TIME}

ABSTRACT: Taking a current edition of the classic story "The Three Little Pigs" as an allegory of childhood's multiplicity of time, intertwined with the research data from my doctorate about age relationships among small children at a public institution of Early Childhood Education, I propose a reflection about childhood age social construction in capitalism in contrast with children's (girls and boys, younger and older) capacities of sociability and production of childhood culture while they are grouped in a education context.

Key words: Early childhood education. Age relationships. Children's literature. Small child. Multiplicity of time.

Doutora em Educação e professora do Departamento de Metodologia de Ensino e Educação Comparada, da Faculdade de Educação da Universidade de São Paulo (USP). E-mail: patypra@ig.com.br 
Três porquinhos irmãos foram morar numa floresta. E para se proteger dos lobos decidiram construir suas casas. $\mathrm{O}$ mais novinho só queria brincar, fez rapidinho uma casinha de palha e saiu a passear. O do meio gostava de tocar flauta. Então, fez uma casinha de madeira e saiu para tocar. O mais velho, prevenido, gastou todo o seu tempo fazendo uma linda casa de tijolos. A noite o lobo resolveu atacar. E num só sopro, derrubou a casinha de palha. O porquinho correu para a casa de madeira do irmão, mas o lobo derrubou esta também. Os dois porquinhos foram à casa do irmão mais velho e ficaram quietinhos esperando. $\mathrm{O}$ lobo chegou e soprou, soprou, soprou, mas não conseguiu derrubar a casa. $\mathrm{O}$ lobo tentou entrar pela chaminé da lareira, mas os porquinhos prevenidos acenderam ali uma fogueira. Quando o lobo chegou perto, chamuscou o rabo no fogo e saiu correndo feito louco e nunca mais voltou. (Contos Clássicos, 2002)

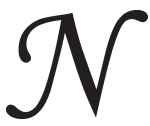

essa edição atual da clássica história Os três porquinhos, encontro uma alegoria articulada à construção da idade como categoria de análise e o início de um fio que pretendo tecer em relação à discussão sobre as temporalidades da infância. Lendo e relendo a história, me vejo num penoso exercício de estranhamento de algo extremamente familiar, como nos ensina a antropologia, profundamente naturalizado. ${ }^{1}$

Procuro saídas na tecitura desse fio, articulando-o com os dados coletados em minha pesquisa de doutorado (Prado 2006) que buscou investigar, através do estudo etnográfico, as relações etárias entre crianças pequenas, de 3 a 6 anos de idade, em uma instituição de educação infantil pública paulista (que integra um Centro Municipal de Educação Infantil e uma Escola Municipal de Educação Infantil, para crianças, filhas e filhos de trabalhadoras(es), de 0 a 3 anos e de 3 a 6 anos de idade, respectivamente). Proponho a reflexão sobre a construção social das idades da infância no capitalismo, em contraponto com as capacidades de sociabilidade e de construção das culturas infantis pelas meninas e meninos, menores e maiores no coletivo educativo. ${ }^{2}$

Se os porquinhos precisavam se proteger do lobo, porque não construíram juntos uma só casa? Se eram irmãos e estavam sozinhos na floresta, porque fizeram casas separadas?

No individualismo que sugere a história, cada porquinho, mesmo com outros irmãos na floresta, desprotegido do lobo, teria que ser responsável por sua própria sobrevivência. Entretanto, somente o irmão 
mais velho é capaz de tal proeza e, sem ele, os porquinhos mais novos sucumbiriam ao lobo. A história propõe, com isso, um sentimento de dependência dos irmãos mais novos em relação ao mais velho, que conquista o poder sobre os mais novos, aparentemente salvando suas vidas.

Entretanto, se o irmão mais velho detinha os conhecimentos necessários para construir uma casa verdadeiramente segura, porque permitiu que os irmãos dormissem nas casas que construíram? Desejaria o irmão mais velho tal poder?

A história recompensa o porquinho mais velho por todo o tempo da infância que lhe foi furtado. Experiente e prevenido, não brincou, nem saiu para passear, tampouco para tocar flauta como os irmãos, mas gastou todo o seu tempo num sentido de utilidade, que se impóe à idade. Teriam os porquinhos mais novos aprendido a lição?

Numa noção de tempo que é para ser gasto, e bem gasto, demarcado, investido, controlado, subjugado, a história revela o sentido imposto pelo capitalismo, marcando arbitrariamente um tempo de experiências que são registradas como fatores causais. Uma noção cronológica, linear, do menor para o maior, é demarcada - metáfora de uma infância que precisa preparar-se para a vida jovem e adulta, madura, séria e produtiva.

Mais do que isso, uma naturalização da infância, estado precário e efêmero, deve encaminhar-se para sua resolução num tempo de estabilidade e maturidade, por meio do acúmulo de experiências e de conhecimentos que caracterizam a vida adulta (como se esta não fosse também provisória). Em estado imperfeito, posto que transitória, inacabada, a infância, assim qualificada na linearidade do tempo cronológico, parece autorizar a opressão, a dominação, o controle e o adultocentrismo.

Contrapondo esta mesma noção de tempo da história apresentada e concebendo-a como fluxo constante, coletivo e mediado, as experimentaçôes e experiências vividas pelos três porquinhos irmãos é que determinam, então, uma temporalidade da infância e não o contrário. Várias dimensóes da experiência temporal devem ser consideradas, além da necessidade de alteração de uma concepção de infância como sinônimo da incapacidade, da inexperiência, do desconhecimento, advindos da pouca idade. 
Refletir sobre a infância e sua temporalidade é, por isso, tão espinhoso quanto falar das dificuldades inerentes para se lidar com um tema de pesquisa emergente, ainda segmentado e acrítico, quando me refiro às idades - invençōes sociais, assim como a infância e seu tempo, ou o seu "não tempo" no capitalismo: "(...) todo o tempo tem de ser consumido, comprado, posto em uso; é ofensivo das classes trabalhadoras permitir-se-lhes simplesmente "passar o tempo"' (Thompson, 1991, p. 77).

Pregando o furto precoce do lúdico e da brincadeira, já denunciado por Marcellino (1990), a história apresentada também desconsidera a condição infantil e a produção das culturas infantis pelos porquinhos, principalmente dos mais novos, pois quase pagam com a própria vida pelo ócio, por ficar à toa, pelo prazer de brincar, passear, tocar flauta viver a infância em sua plenitude.

Silva (2000), pesquisando as crianças grandes e jovens trabalhadoras da zona da mata canavieira pernambucana, também denuncia a supressão do tempo livre, oposto ao tempo da exploração e alienação capitalista, e a inviabilidade da brincadeira nesta mesma lógica ou a ela submetida. $\mathrm{O}$ mesmo autor aponta para a brincadeira, entretanto, como fundamental em qualquer infância, cultura, classe social, gênero, etnia e nacionalidade, pois as crianças "possuem o mesmo desejo, isto é, não querem um tempo não residual do trabalho estranhado, mas um tempo articulado entre a escolarização e o lúdico" (p. 323).

O tempo da produção, como descartável, fragmentado, próprio da racionalidade capitalista, ignora, entretanto, o "tempo total, simultâneo, passado-presente-futuro fundidos em instantes de plenitude" (Perrotti, 1982, p. 27) e, assim, o tempo em que se vive a infância deve ser encurtado, substituído pela seriedade que não torna a casa de tijolos do porquinho mais velho uma "casinha", como descrita na história para se referir às outras casas construídas. No diminutivo também inferioriza-se o porquinho "mais novinho", como que ainda mais desprovido de consciência em relação aos perigos do lobo e de seu poder. Não é por acaso que sua casa é a primeira a ser destruída pelo lobo, e tendo ele se refugiado na casa de madeira do irmão do meio, confirma-se sua ingenuidade e incapacidade de conhecer os reais perigos. Se a casa de madeira tivesse sido destruída primeiro, para qual casa o porquinho do meio fugiria? E se nenhuma das casas tivesse sido destruída, valeria a pena todo o sacrifício do porquinho mais velho? 
A escolha dos materiais para a construção das casas também demonstra uma hierarquia de poder que se revela na leveza e inconsistência da palha pelo porquinho menor, na possível resistência da madeira pelo irmão do meio e na consistência e solidez do tijolo pelo irmão mais velho - o melhor material, a melhor escolha, o melhor porquinho! O único que tem sua casa adjetivada na história: "uma linda casa de tijolos". E as outras casas, o que eram?

Embora punitiva e carregada de preconceitos em relação à infância, a história se contradiz no momento em que os três irmãos, juntos e "prevenidos", vencem o lobo. Mesmo não derrubando a casa de tijolos com o sopro, o lobo já se preparava para invadi-la pela chaminé e devorar os três porquinhos de qualquer forma. De quem teria sido a ideia de colocar fogo na lareira? Certamente, dos irmãos mais novos, pois, se realmente era experiente e prevenido, o porquinho mais velho já deveria ter acendido a lareira para passar a noite. Este, mesmo prevenindo-se dos sopros do lobo, precisou estar com os irmãos mais novos para juntos acenderem a lareira e juntos também sobreviverem.

Não é à toa que, discutindo sobre a produção corporativa para as crianças, Steinberg e Kincheloe (2001) denunciam a crise da infância contemporânea, o medo do isolamento no sentido da ausência de adultos e da inexistência de um espírito de solidariedade - possível somente no final da história, quando os irmãos se veem realmente juntos e compartilhando a mesma experiência aterrorizante. Nesse momento, os conhecimentos e experiências de cada um dos porquinhos são fundamentais para a composição de uma solução que definitivamente combata o lobo, e as idades diluem-se, as competências e habilidades se fundem, se comungam e se complementam.

Este é o desafio maior que se apresenta diante dos preconceitos em relação à infância vista somente como recorte etário e, nesta tentativa paradoxal de trabalhar com o tema da idade como categoria de análise, construo meu objeto de investigação através de sua desconstrução, de sua dissolução. Busco conceber a infância para além de um recorte etário determinante e produtor de relaçóes sociais e de um discurso científico sobre o desenvolvimento infantil e humano como linear e com etapas a serem vencidas. 
Se a infância é um fenômeno etário universal, no qual não é difícil ver a influência exercida pela observação do ciclo natural da vida, ele apresenta-se sob formas diferentes em razão das características históricas e culturais de cada povo. O real interesse de discutir esta questão não reside, portanto, no fato da existência de um fenômeno etário denominado infância, mas nas razões que levam as sociedades a definir o status dessa infância na sua organização social. Isso quer dizer que mais do que ver a infância como um fenômeno biológico, ela é vista como um fenômeno cultural. (Pino, 2004, p. 147)

Diferentemente do tempo imposto pelo capital, a temporalidade da infância é o sentido de sua própria existência. As crianças são seres temporais, assim como os porquinhos na história e, como eles, vivem em mundos temporais não somente por sua constituição, mas pela criação intencional e relativa a que atribuem uma noção de tempo, através das relaçôes que estabelecem, como um dado da consciência que sempre se desdobra. Nossa experiência de tempo e de duração não é um processo linear. A idade como tempo vivido pode ter significados diferentes para as pessoas, em diversas épocas de suas vidas, em diferentes contextos históricos, sociais e culturais.

Assim como para os porquinhos, as experiências das crianças são criadas no tempo e sintetizam o presente, o passado e o futuro. $\mathrm{O}$ agora é experimentalmente fluido e, mesmo parecendo fixo, ele abarca e dá significado ao passado e ao futuro.

O tempo da infância e a sua temporalidade, ou seja, o tempo da infância vivido e experimentado pelas crianças é social, síntese de múltiplos esquemas do tempo, compartilhado e construído nas relações e através delas. Mesmo funcionando como referência para as temporalidades de cada criança, ou de cada porquinho diferentemente, determina e é determinado pelos ritmos sociais coletivos - quando as crianças estão juntas ou quando os três porquinhos encontram-se e dividem a mesma cena na história.

O tempo também regula a emergência de papéis sociais ao longo do desenvolvimento humano, entendido aqui como fenômeno da cultura, e determina normas e expectativas como um sistema de controle social e de hierarquia - vale apontar para a escala de competências e de poderes que propõe a história dos três porquinhos.

Nesta lógica, manifestando-se como sujeitos da soberania e do direito, dotados de plena racionalidade, os seres humanos vão sendo 
ameaçados pelo esgotamento, pois procuram, pretensiosamente, encontrar na sua própria história a fundação da história e da cultura, negando-se ao encontro com sujeitos de naturezas e condições diversas que são.

É importante lembrar que, mesmo aparecendo de forma condensada e modificada, a história dos três porquinhos passou por reelaboraçôes ao longo dos séculos em diferentes culturas, sendo diversamente interpretada, apropriada e transmitida, narrando experiências comuns a toda a humanidade, ao mesmo tempo em que possui particularidades culturais, assim como os contos de fadas também possuem uma história, além da própria história que contam e que deve ser reconstruída. ${ }^{3}$

Segundo Darnton (1986), um estudioso da história cultural francesa, os contos manifestavam o desejo das classes oprimidas de se desvencilharem da condição social inferior em que se encontravam, traduzindo, portanto, efeitos diversos em diferentes tradições, como as burlescas versōes italianas, as dramáticas versões francesas, as bem humoradas versões inglesas ou as horrendas versões alemãs. Apesar do conformismo presente nos escapismos individuais através das condições, dos objetos e seres mágicos, somente por meio da fantasia as desigualdades poderiam ser superadas e outro patamar na escala social poderia ser alcançado.

Para Zilberman (1985), os contos folclóricos eram contados pelos adultos e para os adultos sem restrição à idade, não eram destinados às crianças, nem faziam parte da educação burguesa. Eles eram narrados por lavradores, pescadores, marinheiros, artífices e mendigos, entre outros, e sofreram uma mudança de função, quando adaptados, transmitindo valores burgueses, éticos, morais e religiosos e conformando as crianças a determinado papel social.

A partir do século XVIII, a noção de infância começa a surgir como uma etapa diferenciada, que merece a atenção dos educadores. Os contos passam a ser utilizados como forma de transmissão de hábitos e formação moral do futuro adulto. Atribuí-se ao conto uma função pedagógica, visando à transmissão de valores aos pequenos leitores. (Túbero, 1996, p. 11)

No século seguinte, uma concepção de infância que cria para esta fase da existência uma necessidade de a criança dominar os problemas psicológicos do crescimento, superar decepçôes narcisistas, rivalidades fraternas, dilemas edípicos e integrar sua personalidade, encontrou nos 
contos de fadas (especialmente, nas versões dos irmãos Grimm) um canal para que as crianças abandonassem as dependências infantis, obtendo um necessário sentimento de individualidade. Assim, a infância estaria sob o alicerce fundamental de um modelo ideológico burguês consolidado sob normas, valores e obrigações morais, sobrando aos que não se encaixassem em seu modelo o medo da morte eminente, a condenação ou, ainda, uma espécie de maldição do destino. Uma maldição que, atualmente, parece revelar um tempo e um lugar para a infância, num espaço adultocentricamente dominado, no qual a criança pode ser vista como o centro ou então como um estorvo:

(...) um adulto defeituoso, ainda incompleto, pois seu tempo converte-se em tempo do capital, apenas à medida que vai sendo "adestrada", disciplinada enquanto corpo, dentro da mesma lógica que constrói o espaço-tempo adulto do mundo moderno capitalista. (Márques, 1997, p. 8)

Como coloca Simmel (1983), a vida moderna marcada pela diferenciação social abandona uma hierarquia precedente e coloca os seres humanos na interseção de esferas sociais excêntricas, nas quais, muitas vezes, participam voluntariamente. É através das múltiplas relações que a temporalidade da infância pode ser compreendida e investigada, pensando na capacidade de sociabilidade das crianças, numa elaboração e transformação da realidade da vida, assim como finda a história dos três porquinhos.

A sociabilidade não é dada pela natureza, ela é um produto da cultura, uma elaboração individual e coletiva dos comportamentos e atitudes, uma mediação entre a expressão e o pertencimento, pois ao mesmo tempo em que se manifestam culturalmente, as crianças também constroem seu pertencimento e incorporam valores de seu posicionamento na hierarquia social, se identificam e se diferenciam em relação aos outros (que podem ser seus semelhantes, diferentes, iguais ou desiguais).

Para Simmel (1983), a sociabilidade e a cultura possuem uma relação simbiótica, pois ambas se fundem em cada forma de interação, de comunicação social. É o que acontece nas relações que as crianças pequenas estabelecem nas brincadeiras.

Assim como para os porquinhos da história, as autoras infantis reconhecidas nos espaços das brincadeiras e permeadas pelas culturas 
dos adultos não se dão somente em obras materiais, mas na capacidade de as crianças transformarem a natureza e, no interior das relações sociais, tecerem verdadeiras teias de criações humanas e de redes de sociabilidade (Fernandes, 1979).

As crianças menores e maiores, entretanto, não nascem com o sentido do tempo como demarcação precisa entre o passado, o presente e o futuro, característica das sociedades capitalistas. Elas constroem suas noções temporais e espaciais determinadas, sim, pela cultura à qual pertencem (e vice-versa), mas esta demarcação só se faz possível quando domina uma noção linear do tempo, conjugada à noção de irreversibilidade do tempo (Gourevich apud Almeida, 2004).

Em outras sociedades e grupos sociais não capitalistas, nas quais o calendário não se inclui como um patrimônio do saber compartilhado e naturalizado, é difícil determinar o número dos anos que se viveu, ou as idades. Com isso, outras sequências de acontecimentos são tomadas como referência para padronizações na escala social. O tempo é uma categoria presente em todas as sociedades humanas, mas nem por isso seu sentido é único, já que ele não é uma forma inata de experiência, um dado não modificável na natureza humana ou uma simples representação subjetiva enraizada nesta mesma natureza.

Não há, todavia, um tempo específico e típico das sociedades industriais em contraposição a um tempo e um espaço da infância, pois ambos são construídos historicamente e estão interligados: o tempo da cultura e o tempo do capital. Este último é também cultural e diz respeito às culturas do capitalismo que, por sua vez, envolvem a ideologia, que compreende o sentido de linearidade, como sucessão e devir que não se repetem, numa cronologia necessária a sua própria reprodução e manutenção.

A idade cronológica como marcador social das sociedades modernas ocidentais torna-se uma forma de reconhecimento social da maturação individual e implica um tipo específico de organização da estrutura social (Fortes, 1984). Lutar contra esta ideologia é lutar também contra a transformação das idades em mercadorias, contra uma cronologia do tempo vencedor, do capital, da exploração capitalista e do não ser da infância.

Defendendo a necessidade de pesquisas que tenham as culturas infantis como centro, através do estudo das brincadeiras e formas de 
sociabilidades no tempo e no espaço, na expansão e construção de seu pertencimento no coletivo, entre crianças de idades iguais e diferentes, concebo a idade como categoria, no sentido de ser "tudo aquilo que levamos conosco, que herdamos ao nascer e que vamos criando enquanto vivemos a partir do que o mundo nos diz e tal como se nos apresenta" (Gusmão, 2003b, p. 28).

A idade como tempo vivido pelo corpo, assim descrita por VeigaNeto (2000), ${ }^{4}$ apresenta-se como um elemento de pertencimento que não está isolado de outras categorias identitárias (como as de gênero e de classe social) como se tudo estivesse marcado no corpo (vestuário, corte de cabelo, adereços, modos de falar, marcas físicas).

Assim, o que está em discussão não é a idade em si, biológica ou cronológica, mas como ela é construída, inventada, o que ela significa em cada contexto (especialmente no educativo), em cada momento da vida e da cultura, quais os valores a ela atribuídos, quais as suas características, fundamentos e transformaçôes, quais os sentidos de se ter as idades da infância para as crianças e a partir delas.

Certo dia, as crianças mais velhas do pré perguntaram minha idade e, quando respondi, ficaram perplexas e me chamaram de velha, dizendo que achavam que eu tinha uns vinte anos. Depois disseram que eu era: - Uma pessoa assim... meio nova, meio velha, mas que nem parecia.

Da mesma forma, as crianças menores do maternal costumavam comparar seus tamanhos com outras crianças da mesma turma, como que buscando uma coerência para o mundo posto numa ordem específica, que atribui aos mais velhos maior tamanho também, confrontando-se, experimentando, tirando suas próprias conclusóes. Enquanto mediam seus tamanhos em uma fita marcadora afixada na parede da sala, comparando-os entre si, um menino aproximou-se de uma colega e, percebendo que era bem maior do que ela em tamanho, disse: - Eu estou medindo com ela e nem estou do tamanho dela. Três já é grande!

Quantos anos o menino achava que tinha a colega menor em tamanho? Como poderia ter a mesma idade da colega se era bem maior do que ela? Mas não faziam parte da mesma turma? Em função de que (para as crianças) elas estavam separadas de outras? Por que estavam com aquela turma de crianças e não com outras? Como operavam os 
conhecimentos das crianças, diante da ordem e da lógica institucionalizada?

Observei que os critérios de separação das turmas por idade ainda não estavam totalmente incorporados pelas crianças menores que, assim como as maiores, construíam uma noção de tempo a partir delas próprias e de suas experiências. Elas eram a medida das coisas, mas não num sentido quantitativo. Elas evidenciavam que o tempo, por não ser perceptível, é algo que não se pode ver, tocar, ouvir e, por isso, é algo incapaz de ser captado como faz o relógio pelo processo físico, padronizado pela sociedade, decompondo-o em sequências absolutamente regulares.

Assim, a idade pode ser conceituada no tempo socialmente padronizado pela sociedade, pelo relógio e pelo calendário, para designar, avaliar, compreender e definir processos que não podem ser a ela diretamente cotejados.

Elias (1998) afirma que, ao atentarmos para as questões sociológicas relativas ao tempo, podemos aprender e desvelar coisas sobre nós que as teorias dominantes não permitem apreender. $\mathrm{O}$ conjunto de símbolos do calendário é indispensável à regulamentação das relaçôes sociais, como processo cego, uma segunda natureza, aceita como se fosse parte dos destinos de todos os seres humanos.

Entretanto, a datação e a determinação do tempo em geral estão simultaneamente em processos físicos moldados pelos indivíduos ou independentemente deles, e em observaçôes que abarcam uma síntese conceitual, o que se apresenta numa sucessão, não num conjunto. $\mathrm{O}$ mesmo autor (1998) tem como objetivo saber por que os seres humanos necessitam determinar o tempo como uma forma inata de experiência, um dado não modificável na natureza humana.

As crianças pesquisadas também revelaram que o tempo não é uma representação subjetiva enraizada nessa natureza, pois:

(...) o que está em jogo é a possibilidade de experimentar o mundo, descobri-lo em seus elementos, o que ela (a criança) faz por meio de comparação entre o que vê, ouve e observa, tanto na relação com o adulto, como com outras crianças. $\mathrm{O}$ ato de comparar consiste num ato de conhecimento de si mesmo, do outro, do mundo. (Gusmão, 2003a, p. 203) 
Discutindo sobre a sociologia das ausências, aquela que tem como objetivo transformar os objetos ausentes ou inexistentes em existentes, através da demonstração de que "o que não existe é, na verdade, activamente produzido como não existente, isto é, como uma alternativa não credível ao que existe", Sousa Santos (2005, p. 19-20) apresenta a lógica da monocultura do tempo linear como um dos processos pelos quais os critérios hegemônicos de eficácia e de racionalidade produzem a não existência, do que não lhes cabe.

Ao lado das monoculturas do saber e do rigor do saber; da naturalização das diferenças; do universal e do global e dos critérios de produtividade e de eficácia capitalista, a monocultura do tempo linear assenta sua lógica numa história de sentido e direção únicos e conhecidos, de progresso e de desenvolvimento, tão bem apresentados pela história Os três porquinhos. $\mathrm{Na}$ frente, estão aqueles que são centrais do sistema mundial, seus conhecimentos, instituições, formas de socializações dominantes, produzindo a não existência daqueles ditos atrasados.

Neste caso, a não existência assume a forma de residualização que, por sua vez, tem adoptado, ao longo dos últimos duzentos anos, várias designaçôes, a primeira das quais foi o primitivo ou selvagem, seguida de perto por outras como o tradicional, o pré-moderno, o simples, o obsoleto, o subdesenvolvido. (Sousa Santos, 2005, p. 20)

Para Marramao (1995), as sociedades entendem o poder segundo as noções de temporalidade que nelas circulam e as relações de poder e de dominação são ainda mais resistentes quando assentam sob hierarquias entre temporalidades, numa perspectiva de progresso, também claramente evidenciada na história Os três porquinhos. Refletindo sob este ponto de vista, a infância e suas temporalidades, inscritas na dominação, estão na redução dessa mesma experiência social (dominada), ruidosa e indesejável à condição de resíduo.

As experiências são consideradas residuais porque são contemporâneas de maneiras que a temporalidade dominante não é capaz de reconhecer. São desqualificadas, suprimidas ou tornadas ininteligíveis porque são regidas por temporalidades que não estão contidas no cânone temporal da modernidade ocidental capitalista. (Souza Santos, op. cit., p. 25)

Propondo a substituição das monoculturas por ecologias, a sociologia das ausências (Sousa Santos, 2005) visa libertar as práticas sociais 
de seu estatuto de resíduos, compreendendo as sociedades como constituídas por várias temporalidades, confrontando a ideia de que o tempo linear não é a única concepção do tempo e que seu predomínio não resulta de sua primazia como concepção temporal, mas da primazia da modernidade ocidental que, ainda assim, não eliminou o tempo sazonal, circular, o tempo vivido.

Portanto, o tempo vivido pelas crianças também ainda não foi totalmente eliminado. Vale lembrar que até mesmo a história Os três porquinhos deixou escapar um tempo em que os três irmãos se encontram e compóem juntos a mesma cena, interetária e antietária, no sentido da não priorização de uma determinada idade em função de outras.

Através não somente de uma sociologia, como de uma psicologia, de uma antropologia e de uma pedagogia das ausências, a infância, como objeto ausente ou inexistente, pode existir de fato. A infância pode ser concebida através da lógica da monocultura do tempo linear quando corresponde à temporalidade dos critérios hegemônicos de eficácia e de racionalidade, e se apresenta numa história de sentido único, universal, imutável, também em função do seu progresso e de seu desenvolvimento. $\mathrm{Na}$ frente estão os mais velhos, seus conhecimentos, suas ideologias, seus preconceitos e conceitos, que podem ou não produzir a não existência dos mais novos.

Não somente, a sociologia deve libertar a temporalidade da infância de sua condição residual, compreendendo suas diversas temporalidades possíveis e confrontando a ideia de que o tempo linear, para a compreensão da infância, é apenas uma das muitas concepções do tempo para as crianças, além do tempo experimentado, do tempo confrontado, do tempo transmutado, do tempo festejado, do tempo que não é resíduo.

Do ponto de vista da monocultura do tempo linear, uma psicologia das ausências substituiria um olhar centrado naquilo que as crianças ainda não são por um olhar daquilo que elas são de fato, enquanto são crianças. Uma antropologia das ausências substituiria uma epistemologia centrada no outro por outra, centrada em si mesma (na antropologia) e em seu próprio estranhamento - a infância, o que nela habita, o que dela se compreende. E uma pedagogia das ausências substituiria, nesta lógica, uma relação de dominação, divisão e 
segregação das crianças pela possibilidade educativa de convívio entre as diferenças de classe social, de etnia, de gênero e, principalmente, de idade - na constituição de uma infância existente e presente.

Quais as versões da história Os três porquinhos as crianças pequenas brasileiras contariam? Quais estão sendo contadas para elas e quais conceitos de infância estas privilegiam? De submissão e de reprodução? Ou de resistência, transgressão e invenção?

\section{Notas}

1. "Os Contos infantis, com suas luzes puras e suaves, fazem nascer e crescer os primeiros pensamentos, os primeiros impulsos do coração. São também contos do lar, porque neles a gente pode apreciar a poesia simples e enriquecer-se com sua verdade. E também porque eles duram no lar como herança que se transmite" (Irmãos Grimm apud Darnton, 1986).

2. A coleta de dados da pesquisa deu-se através da observação participante e do uso da fotografia (também realizadas pelas crianças), nos diversos momentos da jornada educativa, com registro posterior em diário de campo. Também realizei entrevistas semiestruturadas com as professoras e conversas informais com as crianças (a partir das fotografias), com a utilização do gravador para registro das entrevistas e de canções das crianças, além da utilização de fontes não convencionais de pesquisa, como a literatura infantil, poesias e produções cinematográficas sobre a temática, no refinamento de metodologias de pesquisa com crianças, como descrito em Faria, Demartini e Prado (2005) e em Filho e Prado (2011).

3. Segundo estudiosos da literatura infantil como Darnton (1986), Túbero (1996), Zilberman (1985), entre outros, os contos de fada constituíram-se através da coleta e adaptação de contos e lendas da Idade Média, inicialmente, por Charles Perrault na França (século XVII), somados à coleta e adaptação de contos folclóricos na Alemanha (século XIX) pelos irmãos Grimm, pelas narrativas diversas de Christian Andersen na Dinamarca, além de Collodi na Itália, Lewis Carol na Inglaterra, Frank Baum nos Estados Unidos, James Barrie na Escócia, entre outros. A história $O$ três porquinhos, especialmente, tem suas primeiras edições no século XVII, mas há quem pense que seja bem mais antiga. Ela foi transformada em versão animada nos desenhos de Walt Disney, em 1933.

4. É importante ressaltar que, para a composição do título deste trabalho, inspirei-me na obra de Veiga-Neto (2000) e em seu conteúdo inovador (e quase inexistente), no que tange as questôes relativas à idade e as temporalidades.

\section{Referências}

ALMEIDA, M.J. As idades, o tempo. Pró-Posiçōes, Campinas, v. 15, n. 1 (43), p. 39-61, jan.-abr. 2004.

BENJAMIN, W. Reflexões: a criança, o brinquedo, a educação. São Paulo: Summus, 1984. 
CONTOS CLÁSSICOS. Os três porquinhos. Erechim: Edelbra, 2002. (n. 7).

DARNTON, R. O grande massacre de gatos e outros episódios da história cultural francesa. Rio de Janeiro: Graal, 1986.

ELIAS, N. Sobre o tempo. Rio de Janeiro: Zahar, 1998.

FARIA, A.L.G.; DEMARTINI, Z.B.; PRADO, P.D. (Org.). Por uma cultura da infância: metodologias de pesquisa com crianças. 2. ed. Campinas: Autores Associados, 2005.

FERNANDES, F. Folclore e mudança social na cidade de São Paulo. 2. ed. Petrópolis: Vozes, 1979.

FILHO, A.J.M.; PRADO, P.D. (Org.). Das pesquisas com crianças à complexidade da infância. Campinas: Autores Associados, 2011.

FORTES, M. Age, generation and social structure. In: KERTZER, D.; KEITH, J. (Org.). Age and anthropological theory. New York: Cornell University, 1984. p. 137-184.

GUSMÃO, N.M.M. Antropologia, processo educativo e oralidade: um ensaio reflexivo. Pró-Posições, Campinas, v. 14, n. 1 (40), jan.-abr. 2003a.

GUSMÃO, N.M.M. Infância e velhice: desafios da multiculturalidade. In: GUSMÃO, N.M. M. (Org.). Infância e velhice: pesquisa de ideias. Campinas: Alínea, 2003b. p. 15-32.

MARCELlinO, N.C. Pedagogia da animação. Campinas: Papirus, 1990.

MÁRQUES, F.T. A maldição das ruas: o estigma do pivete. 1997. Dissertação (mestrado) - Universidade Estadual Paulista, Araraquara.

MARRAMAO, G. Poder e secularização: as categorias do tempo. São Paulo: Editora da Unesp, 1995.

PERROTTI, E. A criança e a produção cultural. In: ZILBERMAN, R. (Org.). A produção cultural para a criança. Porto Alegre: Mercado Aberto, 1982. p. 9-27.

PINO, A. Infâncias e culturas: semelhanças e diferenças. In: GALLO, S.; 
SOUZA, R.M. (Org.). Educação do preconceito: ensaios sobre poder e resistência. Campinas: Alínea, 2004. p. 147-164.

PRADO, P.D. Contrariando a idade: condição infantil e relações etárias entre crianças pequenas da educação infantil. 2006. Tese (doutorado em Educação) - Faculdade de Educação da Universidade Estadual de Campinas, Campinas.

SIMMEL, G. Georg Simmel: Sociologia. São Paulo: Ática, 1983.

SILVA, M.R. $O$ assalto à infância no amargo da cana-de-açúcar: Onde está o lazer/lúdico? O gato comeu? 2000. Tese (doutorado em Educação) - Faculdade de Educação da Universidade Estadual de Campinas, Campinas.

SOUSA SANTOS, B. O Fórum Social Mundial como epistemologia do Sul. In: O Fórum Social Mundial: manual de uso. Porto: Afrontamento, 2005. p. 17-32.

STEINBERG, S.R.; KINCHELOE, J.L. (Org.). Cultura infantil: a construção corporativa da infância. Rio de Janeiro: Civilização Brasileira, 2001 .

THOMPSON, E.P. O tempo, a disciplina do trabalho e o capitalismo industrial. In: SILVA, T.T. (Org.). Trabalho, educação e prática social. Porto Alegre: Artes Médicas, 1991. p. 44-93.

TÚBERO, A.S.S. As múltiplas faces da chapeuzinho e do lobo: as relações de gênero do conto Chapeuzinho Vermelho. 1996. Dissertação (mestrado) - Universidade Estadual Paulista, Araraquara.

VEIGA-NETO, A. As temporalidades do corpo: (material)idades, (divers)idades, (corporal)idades, (ident)idades. In: AZEVEDO, J.C. et al. (Org.). Utopia e democracia na educação cidadã. Porto Alegre: Editora da UFRGS; SME, 2000. p. 215-234.

ZILBERMAN, R. A literatura infantil na escola. 5. ed. São Paulo: Global, 1985.

Recebido em 10 de junho de 2009.

Aprovado em 20 de novembro de 2011. 